\title{
Generate Rich Fluorescence in a Simple Polystyrene System through Solvent Removal and Molecular Interactions
}

\author{
$\underline{\text { Alex Kuo }}$ \\ Researcher, 83 Borough Drive, Toronto, Ontario, Canada, M1P 5E4 \\ alex1.kuo2@yahoo.com
}

doi:10.5618/chem.2011.v1.n1.1 || Received: 21-03-2011, Accepted: 13-04-2011, Available online: 29-04-2011

\begin{abstract}
With solvent evaporation, polystyrene fine particles are found to exhibit an unusual fluorescence change from possessing a typical excimer emission band centered at $330 \mathrm{~nm}$ to a variety of strong structured bands at longer wavelength with maxima at $356 \mathrm{~nm}$, $365 \mathrm{~nm}, 372 \mathrm{~nm}, 383 \mathrm{~nm}, 404 \mathrm{~nm}$ and $426 \mathrm{~nm}$. Similar fluorescence emissions are also observed in polystyrene film after solvent removal. The excitation spectra observed by monitoring these fluorescence emissions at the wavelengths of maxima reveal fluorescence is emitted from different fluorophores. The folding of polystyrene chains during the preparation of polystyrene fine particles through reprecipitation and polystyrene chain relaxation during solvent evaporation are believed to be prerequisites for the formation of different fluorophores via phenyl aggregations, while the aromaticaromatic interactions between the pendant phenyl groups on polystyrene chains are considered to bring a powerful driving force for the formation of fluorophorous phenyl aggregations responsible for the observed fluorescence phenomena. This discovery can contribute to understanding and control of molecular interactions in aromatic systems, especially aromatic macromolecule systems. The luminescence can be used to manufacture light devices and other hybrid materials, as well as to probe local environment in aromatic systems.
\end{abstract}

Keywords: fluorescence; polystyrene; solvent evaporation, molecular interactions; chain relaxation; aromaticaromatic interactions.

\section{Introduction}

Molecular interactions are interactions between molecules, typically macromolecules, through different types of non-covalent bonds. The most commonly mentioned types of non-covalent interactions include ionic bonds, hydrophobic interactions, hydrogen bonds and van der
Waals forces (VDW) (namely, dipole-dipole, dipoleinduced dipole interactions, and dispersion attractions). They all play important roles in molecular assembly and structure control. For instance, hydrogen bonding and hydrophobic interactions are primarily responsible for the three-dimensional structures of biopolymers, such as proteins, nucleic acids, and cell membranes.

There are some other molecular interactions that occur to specific systems: halogen bonding and aromatic interactions. Although the first report of halogen bonding, an analogue to hydrogen bonding that occurs between a halogen atom (I, Br, Cl, and sometimes $\mathrm{F}$ ) rather than hydrogen atom and a Lewis base, can be traced back to 1963 [1], theoretical studies [2-6] of halogen bonding and its applications in material engineering [7-12] and biological macromolecules [1315] attract scientists' interest from time to time.

Aromatic interactions are molecular forces involving $\pi$-electron rich molecules, which include cation- $\pi$ [16$25], \pi-\pi$ (aromatic-aromatic) [26-30], and X-H-- $\pi$ [31-32] interactions. The main energetic contributions to these interactions are VDW dispersion and electrostatic interaction. Although aromatic interactions have been implicated in different fields, such as asymmetric catalysis, DNA stabilization, drug intercalation, protein structure and supramolecular chemistry, these interacttions are still being actively debated in the literature.

Each given non-covalent interaction is relatively weak, often with a free energy of less than RT, but the cumulative energies of non-covalent interactions could be huge. For instance, huge numbers of small noncovalent forces drive the spontaneous folding or unfolding of proteins and nucleic acids. Unfortunately non-covalent interactions are complex and remain poorly understood.

This work investigates the fluorescence of a simple system of polystyrene fine particles, as well as polystyrene film. In as-prepared polystyrene particles, the fluorescence is dominated by polystyrene excimer emission. With solvent evaporation, polystyrene par- 
ticles and film exhibit rich fluorescence with strong structured bands that were never previously reported. The excitation spectra at wavelengths of fluorescence maximum intensities show different absorption bands, implying different fluorophores formed in the system. The observed luminescence is elucidated from the views of chain folding, relaxation and molecular interactions.

\section{Materials and methods}

Spectroscopic-grade methanol and tetrahydrofuran (THF) were used without further purification. Polystyrene samples purchased from Polymer Source were of narrow molecular weight distribution standards. The molecular weights and polydispersities were $\mathrm{M}_{\mathrm{w}}=$ 223,000 and $\mathrm{M}_{\mathrm{w}} / \mathrm{M}_{\mathrm{n}}=1.06$, respectively. The polystyrene fine particles were prepared by reprecipitation of $0.021 \mathrm{~g} / \mathrm{ml}$ polystyrene/THF solution in methanol. The precipitated polystyrene particles were washed a few times with methanol, and then deposited on a piece of quartz plate. The deposited polystyrene particles were allowed to dry in air at room temperature for a few hours before fluorescence measurements. The polystyrene film was cast on a quartz plate from the same polystyrene solutions. The film was left to dry in air and then vacuum at room temperature.

Fluorescence spectra of the polystyrene particles, film and solution were obtained with a Jobin-Yvon SPEX F212 using the front-face mode at room temperature $\left(\sim 25^{\circ}\right)$. The slit widths were set to $0.5 \mathrm{~nm}$ for all measurements. Each reported spectrum was an average of two to three separate scans to reduce noise.

\section{Results and discussion}

The fluorescence spectra recorded at excitation wavelength of $260 \mathrm{~nm}$ on polystyrene particles after different extents of drying are presented in Fig. 1. The asprepared polystyrene particles only exhibit a typical excimer fluorescence emission band centered at $\sim 330$ $\mathrm{nm}$ (labeled as 0 in Fig. 1). When the particles are left under ambient conditions to allow solvent to evaporate freely for three days, the emission band shifts to longer wavelength and the major peak is split into two equal shoulders at $326 \mathrm{~nm}$ (1) and $339 \mathrm{~nm}$ (2). Some tiny shoulders appeared in 330-420 nm range which look like noise and appear negligible. This observation leads to the conclusion that solvent evapora-tion from polystyrene particles can change their fluorescence emissions. The polystyrene particles were then subjected to a vacuum of $10^{-2}$ Torr for faster solvent removal. It was found that, after one day of vacuum enhanced drying, the tiny shoulders in the long wavelength of fluorescence spectrum become much more evident and cannot be ignored. After a week of vacuum drying, the fluorescence of polystyrene particles are dominated with a variety of strong structured bands at longer wavelength with maxima at $347 \mathrm{~nm}(3), 356$ $\mathrm{nm}(4), 365 \mathrm{~nm}(5), 372 \mathrm{~nm}(6), 383 \mathrm{~nm}$ (7), $404 \mathrm{~nm}$ (8) and $426 \mathrm{~nm}(9)$. These fluorescence emissions continue to grow stronger with further enhanced vacuum-drying. Although the fluorescence of polystyrene has been widely studied, this phenomenon was never previously reported. Polystyrene fluorescence is generally considered to be made up of monomer and excimer-like emission features. Gupta et al. [33] reported a fluorescence spectrum $\left(\lambda_{\text {ex }}=250 \mathrm{~nm}\right)$ of polystyrene film cast from $\mathrm{CH}_{2} \mathrm{Cl}_{2}$ solution that was mainly contributed from the polystyrene excimer. The spectrum showed a non-structured broad band centered at $\sim 326 \mathrm{~nm}$ that looks similar to as-prepared polystyrene particles in this work (band 0 in Fig. 1). Interestingly, in the fluorescence spectrum of polystyrene thin film prepared from polystyrene solution in chloroform and dried in air at room temperature (S. Abd El Mongy, [34]), there are a strong peak at $404 \mathrm{~nm}$ (the same as peak 8 in Fig. 1) and three other relative strong peaks at around $390 \mathrm{~nm}$ (between peaks 7 and 8 in Fig. 1), 426 $\mathrm{nm}$ (the same as peak 9 in Fig. 1) and $452 \mathrm{~nm}$ (not very evident in Fig. 1). However the work of El Mongy was mainly focused on the spectral changes of doped polystyrene with Rhodamine $6 \mathrm{G}$ and no discussions were made to the fluorescence of polystyrene.

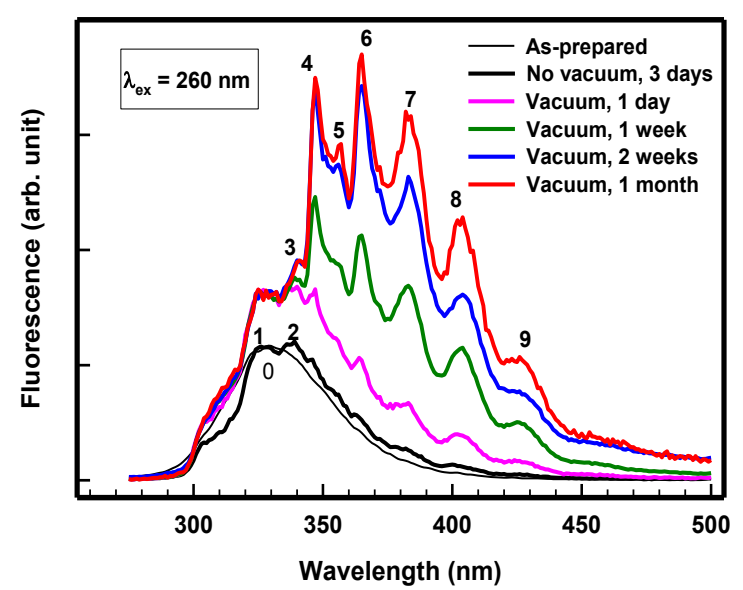

Fig. 1. Fluorescence of polystyrene particles at excitation wavelength of $260 \mathrm{~nm}$. The intensities of fluorescence are normalized for comparison.

Is this fluorescence emitted from different fluorophores? The excitation spectra (1-9) are monitored and summarized in Fig. 2 at the wavelengths of fluorescence maxima on the polystyrene particles after 2 weeks' vacuum drying. These excitation spectra of vacuumpolystyrene particles (1-9) are compared to that of asprepared polystyrene particles (0) at the wavelength of 
excimer emission $330 \mathrm{~nm}$ in Fig.2. The numeric labels 0-9 used in Fig. 2 are corresponding to fluorescence maxima labeled by the same numbers in Fig.1. All fluorescence shows a strong absorption of monobenzene at 254-275 $\mathrm{nm}$. This indicates that the excitation of a single phenyl group can lead to the rich fluorescence emissions by either forming new fluorophores with other phenyl group(s) in the right geo-

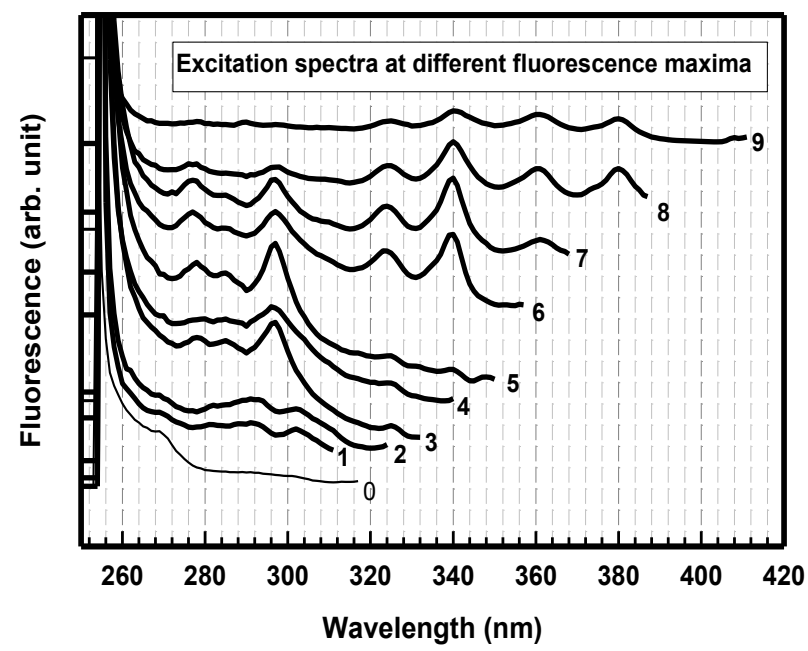

Fig. 2. Excitation spectra of as prepared polystyrene particles (0), and polystyrene particles after 2 weeks of vacuum-drying (1-9). (0-9) excitation spectra were recorded at the wavelengths of fluorescence maxima labeled by the same numbers in Fig. 1: 0) 320nm; 1) 326 $\mathrm{nm}$; 2)339 nm; 3) $347 \mathrm{~nm}$; 4)356 nm; 5) $365 \mathrm{~nm}$; 6) 372 $\mathrm{nm}$; 7) $383 \mathrm{~nm}$; 8) $404 \mathrm{~nm}$; 9) $426 \mathrm{~nm}$. The spectra are intentionally offset on the y-axis to allow them to be individually distinguishable.

metries or/and energy transfer to other fluorophores via radiation. Besides the absorption band of monobenzene, some emissions show a few strong absorptions at longer wavelength such as $296 \mathrm{~nm}, 324 \mathrm{~nm}, 340 \mathrm{~nm}$, $360 \mathrm{~nm}$, and $380 \mathrm{~nm}$, suggesting a few dominate modes of formations of fluorophores. Since phenyl groups are the only fluorophorous unit in polystyrene molecules, these fluorophores must be phenyl aggregations in different geometries and different numbers of phenyl groups. Most fluorescence emission bands are overlapped with each other, therefore it is hard to attribute a single absorption band to a specific fluorescence emission. Furthermore, the excitation of a specific fluorophore can lead to the emission of fluorescence from other fluorophores through energy transfer.

The excitation spectrum labeled as 0 in Fig. 2 corresponds to the polystyrene excimers emission at $330 \mathrm{~nm}$ (label as 0 in Fig. 1) in as-prepared polystyrene. It exhibits a weak peak at $270 \mathrm{~nm}$ besides the strong absorption band of mono-benzene. This absorption peak at $270 \mathrm{~nm}$ is not consistent with the observed absorption band at $291 \mathrm{~nm}$ that was assigned as polystyrene excimer absorption by Healy et al. [35] in their study of polystyrene near the critical concentration c*. Li et al. [36] claimed the observed absorption at around $290 \mathrm{~nm}$ in polystyrene (PSt) as a new UV absorption band that is attributed to associative interaction between pendant phenyl groups. However, when the polystyrene particles are dried in different conditions, as shown in Fig. 3, it is found that absorption peak at $291 \mathrm{~nm}$ (3) did appear, along with more absorption peaks, namely 282 (2) and $302 \mathrm{~nm}$ (4).

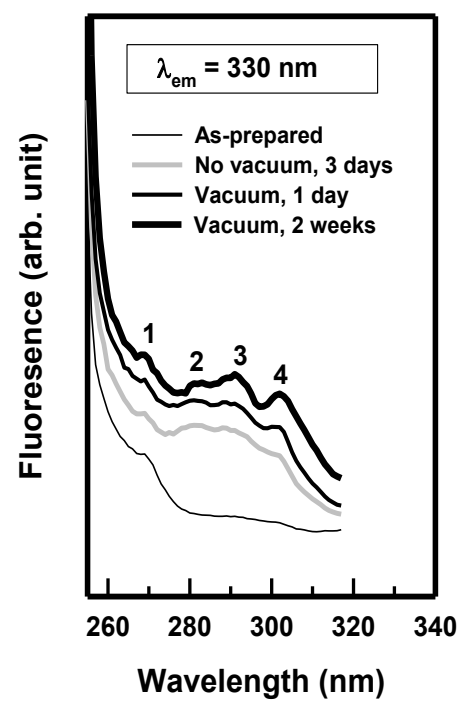

Fig. 3. The excitation spectra of polystyrene particles at $\lambda_{\mathrm{em}}=330 \mathrm{~nm}$ after different drying processes. The labeled adsorption bands are centered: 1) $270 \mathrm{~nm}$; 2) $282 \mathrm{~nm}$; 3) $291 \mathrm{~nm}$ and 4) $302 \mathrm{~nm}$. The spectra are rescaled in y-axis for comparison.

Healy et al. [35] did also observe a relatively sharp peak at $302 \mathrm{~nm}$ and they attributed it to Raman scattering without reasoning. For dried polystyrene particles, the fluorescence at excitation wavelengths of the observed absorption bands $(270,282,291$, and $301 \mathrm{~nm})$ all has similar emission profile to the fluorescence at excitation wavelength of $260 \mathrm{~nm}$ shown in Fig. 1. Therefore there are two possibilities for the observation of more absorption bands: 1) With further drying of polystyrene particles, there are more fluorescence emissions at longer wavelength than that of polystyrene excimer at $330 \mathrm{~nm}$, and some of these fluorescence are overlapped with the excimer emission at $330 \mathrm{~nm}$, therefore the 
excitation spectrum at $\lambda_{\text {em }}=330 \mathrm{~nm}$ has the contributions from the emissions other than that of excimer at $330 \mathrm{~nm}$. 2) More polystyrene excimers in different geometries are formed in the course of drying. The excitations of these excimers can lead to their characteristic fluorescence and fluorescence at longer wavelength by energy transfer.

Fig. 4. presents fluorescence emissions of dried polystyrene particles, monitored at three excitation energies corresponding to three absorption peaks in Fig. 2 centered at $296 \mathrm{~nm}, 324 \mathrm{~nm}$ and $360 \mathrm{~nm}$, respectively. The fluorescence at $\lambda_{\mathrm{ex}}=296 \mathrm{~nm}$ has similar emission profile to the fluorescence at $\lambda_{\mathrm{ex}}=260 \mathrm{~nm}$ in Fig. 1, and fluorescence at $\lambda_{\mathrm{ex}}=270,282,291$, and $301 \mathrm{~nm}$ (not shown). This indicates that both directly excitation of the right fluorophorous unit(s) and energy transfer from the excited fluorophorous unit(s) to other fluorophorous unit(s) with different emissions all contribute to the observed fluorescence emissions. However, excitation at $324 \mathrm{~nm}$ has little contribution to the fluorescence emissions in shorter wavelength than $370 \mathrm{~nm}$, while its major contribution is to the fluorescence emission between $370-400 \mathrm{~nm}$, as indicated by the sharp fluorescence peaks at $372 \mathrm{~nm}, 383 \mathrm{~nm}$, and $392 \mathrm{~nm}$. Excitation at $340 \mathrm{~nm}$ exhibits similar fluorescence profile as excitation at $324 \mathrm{~nm}$. Excitation at $360 \mathrm{~nm}$ has

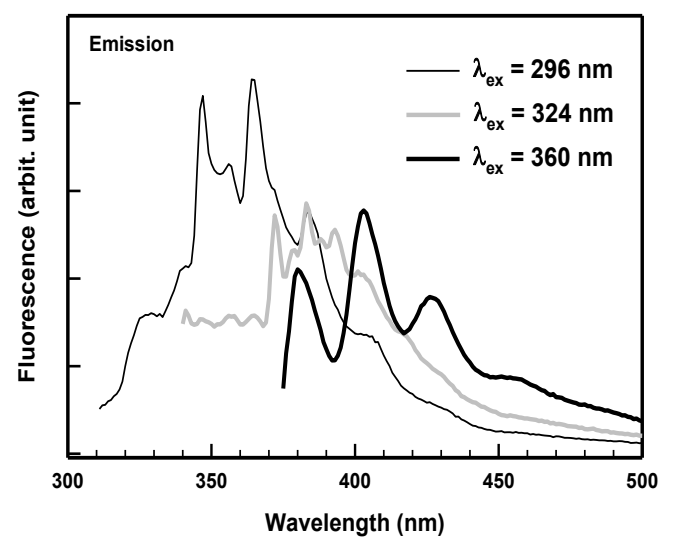

Fig. 4. The fluorescence emission spectra of polystyrene particles at different excitation energies: $\lambda_{\mathrm{ex}}=296 \mathrm{~nm}$, $\lambda_{\mathrm{ex}}=326 \mathrm{~nm}$, and $\lambda_{\mathrm{ex}}=360 \mathrm{~nm}$, respectively. The spectra are rescaled in y-axis for comparison.

major contribution to the fluorescence emissions at 383 , 404 , and $426 \mathrm{~nm}$. Fluorescence emission at $452 \mathrm{~nm}$ observed by S. Abd El Mongy [34] for polystyrene thin film is weak but detected here. Excitation at $380 \mathrm{~nm}$ has similar fluorescence profile as excitation at $360 \mathrm{~nm}$. In general, fluorescence profiles of dried polystyrene particles can be categorized into the three types as shown in Fig. 4 from left to right according to excitation wavelengths: 1) 260-301 nm; 2) 324 and $340 \mathrm{~nm}$; 3) 360 and $380 \mathrm{~nm}$, respectively. The fluorophores with excitation energies that fall into the same wavelength range might have the same number of phenyl groups. Different wavelength ranges might indicate aggregations in different numbers of phenyl groups.

What are the driving forces for the rich fluorescence emissions shown in Fig. 1 and the various fluorophores with different excitation wavelengths as shown in Fig. 2? In other words, what are the driving forces for phenyl aggregations in different geometries and different phenyl numbers in the studies polystyrene system?

First, the polystyrene fine particles were prepared from reprecipitation. Due to solvation by the good solvent THF, polystyrene molecules are dissolved as random coil form in THF. When the polystyrene/THF solution is dropping in the poor solvent methanol, desolvation of polystyrene molecules starts to form the compact folding of the polystyrene chain and polystyrene molecules grow to small nuclei of particles, which is similar to the process that nonspecific hydrophobic interactions drive polypeptide folding to a reasonably stable and compact state prior to further folding of proteins to adopt unique and well-defined structures through dense complementary side chain packing [37]. This allows the phenyl groups of polystyrene molecules in a close proximity for successive growth of fluorophorous phenyl aggregations. Fig. 5 shows a comparison of fluorescence emissions recorded at $\lambda_{\mathrm{ex}}=260 \mathrm{~nm}$ for polystyrene particles reprecipitated from polystyrene solution in THF, polystyrene film cast from polystyrene solution in THF, as well as polystyrene solutions in THF. The spectra of two solid polystyrene samples were dried in similar extent that all exhibit strong fluorescence emissions. It is obvious that, in longer wavelength than $330 \mathrm{~nm}$ of polystyrene excimer emission, polystyrene fine particles exhibit much stronger fluorescence emissions than polystyrene cast film. This indicates that the reprecipitation process does facilitate the formations of fluorophorous phenyl aggregations. The fluorescence weak band observed at $285 \mathrm{~nm}$ for the polystyrene solution in Fig. 5 is the emission from polystyrene monomer [35]. The missing of $285 \mathrm{~nm}$ emission in the studied polystyrene particles and film must result from the nonradiative energy transfer. 


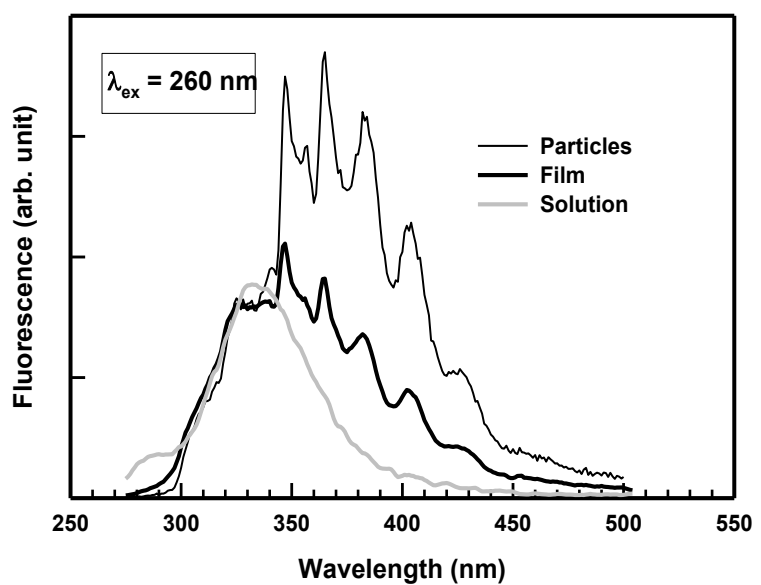

Fig. 5. The fluorescence spectra of polystyrene particles, film and solution $(0.21 \mathrm{~g} / \mathrm{ml}$ in THF $)$ at excitation wavelength of $260 \mathrm{~nm}$.

Second, the experiments show that the formations of phenyl fluorophores and their fluorescence other than excimer emission occur in the course of solvent evaporation. Many studies have showed that solventevaporation conditions have significant effects on the morphology of polymer thin films [38-42]. Solvent allows freedom of movement of polymer chains. As the solvent evaporates, polymer chains become increasingly restricted in movement and the entanglement of polymer chains. In a cast film, solvent evaporation from a solution constrained in two dimensions by a substrate results in one-dimensional thickness reduction and molecular relaxation [43]. The molecules relax and orient through effective stretching of polymer in the planar direction during thickness reduction [43]. The resulting molecular orientation depends on the evaporation rate [43]. In the polystyrene system, the thickness reduction can make the polymer chains in more compact status and therefore the phenyl groups are in closer distance. During the molecular relaxation, some molecular interactions may drive the formation of fluorophorous phenyl aggregations. This is the aromaticaromatic interactions that are going to discuss next.

Third, studies have proved that there are aromaticaromatic interactions between pendant phenyl groups existed in polystyrene systems [36, 44-46]. A wellexamined example of aromatic-aromatic interactions is the benzene dimer. According to theoretical investigations [47-60], benzene dimer exists in different geometries: the parallel-displaced (PD), the T-shaped (T) and the sandwich (S) structures. The PD and T structures are energy minima, while the $\mathrm{S}$ structure is a transition state linking the two minima. The energetics and structure of the benzene trimer and higher clusters/aggregations have also been investigated [6166]. Although the three types of fluorescence profiles shown in Fig. 4 may imply three groups of phenyl fluorophores, each having the same number of phenyl groups, without further investigations, it is hard to convince how many phenyl groups are engaged in the aggregations responsible for the observed fluorescence emissions in the studied polystyrene systems and the geometries of these phenyl aggregations. The more phenyl groups are involved, the more of $\pi$-electrons are delocalized in the interacting system, resulting in fluorescence in longer wavelengths. The rich fluorescence emissions and the association excitation peaks suggest that aromatic-aromatic interactions are pronounced in the studied polystyrene particles and film. These pronounced interaction drive the folding of polystyrene chains to form phenyl aggregates adopted defined structures. They are comparable to the complementary side chain stacking that drives the folding of proteins to adopt unique and well-defined structures [37].

\section{Summary}

In summary, it has been demonstrated that there are unusual rich fluorescence emissions occurred in polystyrene fine particles and film with solvent evaporation. These emissions show various absorptions bands in the excitation spectra, suggesting formation of different fluorophores. Based on the fluorescence profiles, the excitation wavelengths can be categorized into three ranges and each range exhibits similar fluorescence profile. The folding of polystyrene in the preparation of polystyrene fine particles through reprecipitation and polystyrene chain relaxation during solvent evaporation are believed to be prerequisites for the formation of the fluorophores via phenyl aggregations. Pendant phenyl groups on polystyrene chains, as an origin of aromatic-aromatic interaction, brings a powerful driving force for the formation of fluorophorous phenyl aggregations.

Although further investigations are needed to fully understand the observed fluorescence phenomena, this work can add invaluable information to the understanding of molecular interactions in aromatic system, especially aromatic polymers, proteins and other biomacromolecues containing aromatic units. The observed fluorescence emissions can be used to manufacture light devices or other hybrid materials with nanoparticles. The luminance property can also be used as a probe for local environment and molecular relaxation in aromatic compounds or macromolecules. 


\section{References}

[1]Guthrie, F., Xxviii.-On the Iodide of Iodammonium, J. Chem. Soc 1863, 16, 239-244. doi: $10.1039 /$ js 8631600239

[2] Mulliken, R.S. J. Am. Chem. Soc.1950, 72 (1), 600, doi: $\underline{10.1021 / j a 01157 \mathrm{a} 151}$

[3] Mulliken, R.S. J. Am. Chem. Soc.1952, 74 (3), 811824, doi: $10.1021 / \mathrm{ja} 01123 \mathrm{a} 067$

[4] Mulliken, R.S. J. Phys. Chem. Soc. 1952, 56 (7), 801-822, doi:10.1021/j150499a001

[5] Forni, A. Experimental and Theoretical Study of the Brø*N Halogen Bond in Complexes of 1,4Dibromotetrafluorobenzene with Dipyridyl Derivatives. J. Phys. Chem. A 2009, 113, 34033412. doi:10.1021/jp8107182

[6] Politzer, P.; Murray J. S.; Clark, T. Halogen bonding: an electrostatically-driven highly directional noncovalent interaction. Phys. Chem. Chem. Phys. 2010, 12, 7748-7757. doi:10.1039/c004189k

[7]Yabe-nishimura, C. Aldose reductase in glucose toxicity: a potential target for the prevention of diabetic complications. Pharmacol Rev 1998, 50 (1), 21-33. doi:10.1039/c004189k

[8] Nguyen, L.; Al, H. et; Hursthouse, M.B.; Legon, A.C.; Bruce, D.W. Halogen Bonding: A New Interaction for Liquid Crystal Formation. J. Am. Chem. Soc. 2004, 126 (1), 16-17. doi: $10.1021 / \mathrm{ja} 0369941$

[9] Metrangolo, P.; Resnati, G.; Pilati, T.; Liantonio, R.; Meyer, F. Engineering Functional Materials by Halogen Bonding. J. Polym. Sci. Part A: Polym. Chem 2007, 45 (1): 1-14. doi:10.1002/pola.21725

[10]Sun, A.; Lauher, J.W.; Goroff, N.S. (), "Preparation of Poly(Diiododiacetylene), an Ordered Conjugated Polymer of Carbon and Iodine", Science 2008, 312 (5776): 1030-1034. doi: $10.1126 /$ science.1124621

[11] Pigge, F.; Vangala, V.; Kapadia, P.; Swenson, D.; Rath, N. Hexagonal Crystalline Inclusion Complexes of 4-Iodophenoxy Trimesoate. Chem, Comm 2008, 38, 4726-2728. doi:10.1039/b809592b

[12]Metrangolo, P.; Resnati, G.; Pilati, T.; Terraneo, G.; Biella, S. Anion coordination and anion-templated assembly under halogen bonding control. CrystEngComm 2009, 11 (7), 1187-1196. doi: $10.1039 / \mathrm{B} 821300 \mathrm{C}$

[13] Steinrauf, L.K.; Hamilton, J.A.; Braden, B.C.; Murrell, J.R.; Benson, M.D. X-ray crystal structure of the Ala-109--> Thr variant of human transthyretin which produces euthyroid hyperthyroxinemia. $J$. Biol. Chem. 1993, 268 (4), 2425-2430.
[14] Howard, E.I.; Sanishvili, R; Cachau, R.E.; Mitschler, A.; Chevrier, B.; Barth, P.; Lamour, V.; Van Zandt, M. Ultrahigh resolution drug design I: Details of interactions in human aldose reductaseinhibitor complex at $0.66 \AA$. Proteins: Structure, Function, and Bioinformatics 2004, 55 (4), 792-804. doi: $10.1002 /$ prot.20015

[15] Auffinger, P. ; Hays, F.A.; Westhof, E; Ho, P.S. Halogen Bonds in Biological Molecules, Proc. Natl. Acad. Sci. U.S.A 2004, 101(48), 16789-16794, doi: $10.1073 /$ pnas.0407607101

[16] Deakyne, C.A.; Meot-Ner, M. J. Am. Chem. Soc. 1985, 107, 474-479. doi:10.1021/ja00288a034

[17] Burley, S. K.; Petsko, G. A. Science, 1985, 229, 23 28. doi: $10.1126 /$ science. 3892686

[18] Shepodd, T. J.; Petti, M. A.; Dougherty, D. A. J. Am. Chem. Soc., 1988, 110, 1983. doi:10.1021/ja00214a063

[19] Kumpf, R.A.; Dougherty, D.A. Science, 1993, 261, 1708-1710. doi:10.1126/science. 8378771

[20] Dougherty, D. A. Science, 1996, 271, 163-168. doi:10.1126/science.271.5246.163

[21] Gallivan, J. P.; Dougherty, D. A. Proc. Natl. Acad. Sci. U.S.A. 1999, 96, 9459-9464. doi:10.1073/pnas.96.17.9459

[22] Gallivan, J. P.; Dougherty, D. A., J. Am. Chem. Soc., 2000, 122 (5), 870-874. doi:10.1021/ja991755c

[23] Smith, J. M.; Holland, P. L. J. Am. Chem. Soc., 2001, 123, 9222-9223. doi:10.1021/ja016094+

[24] Bartoli, S.; Roelens, S. J. Am. Chem. Soc., 2002, 124, 8307-8315. doi:10.1021/ja025884w

[25] Yamada, S.; Morita, C. J. Am. Chem. Soc., 2002, 124, 8184-8185. doi:10.1021/ja0203317

[26] Hunter, C.A.; Sanders, J.K. M. J. Am. Chem. Soc.1990, 112, 5525-5534. doi:10.1021/ja00170a016

[27] Anelli, P.L.; Spencer, N.; Stoddart, J.F. J. Am. Chem. Soc. 1991, 113, 5131-5133. doi:10.1021/ja00013a096

[28] Hunter, C. A.; Singh, J.; Thornton, J. M. J. Mol. Biol. 1991, 218, 837-846. doi:10.1016/00222836(91)90271-7

[29] Bissell, R.A.; Cordova, E.; Kaifer, A.E.; Stoddart, J.F. Nature 1994, 369, 133-137. doi: $10.1038 / 369133 \mathrm{a} 0$

[30] Kolb, H.C.; Andersson, P.G.; Sharpless, K.B. J. Am. Chem. Soc.1994, 116, 1278. doi:10.1021/ja00083a014 
[31] Perutz, M. F.; Fermi, G.; Abraham, D. J.; Poyart, C.; Bursauz, E. J. Am. Chem. Soc.1986, 108, 1064-1078. doi:10.1021/ja00265a036

[32] Noyori, R.; Ohkuma, T. Angew. Chem., Int. Ed. Engl. 2001, 40, 40. doi:10.1002/15213773(20010105)40:1<40::AID-ANIE40>3.0.CO;2-5

[33] Gupta, M.C.; Gupta, A.; Horwitz, J.; Kliger, D. Time-Resolved Fluorescence and Emission Depolarization Studies on Polystyrene: Photochemical Processes in Polymeric Systems, Macromolecules 1982, 15, 1372-1376. doi:10.1021/ma00233a031

[34] S. Abd El Mongy,Preparation and Spectroscopic Studies of Rhodamine 6G Doped Polystyrene, Aust. J. Basic \& Appl. Sci. 2009, 3(3): 1954-1963.

[35] Healy, M. S.; Hanson, J. E. Fluorescence excitation spectroscopy of polystyrene near the critical concentration $c^{*}$, Journal of Applied Polymer Science, 2007, 104, 360-364. doi:10.1002/app.24796

[36] Li, T.; Zhou, C.; Jiang, M. UV absorption spectra of polystyrene. Polymer Bulletin 1991, 25(2), 211216. doi:10.1007/BF00310794

[37] Tanford, C. How protein chemists learned about the hydrophobic factor, Protein Science, 1997, 6, 13581366. doi: $10.1002 /$ pro.5560060627

[38] Dalnoki-Veress, K.; Forrest, J.; Stevens, J.; Dutcher, J. Physica A 1997, 239, 87-94.

[39] Kim, G.; Libera, M. Macromolecules 1998, 31, 2569-2577. doi:10.1021/ma971349i

[40] Woo, E.; Su, C. Polymer 1996, 37, 5189-5196. doi:10.1016/0032-3861(96)00350-3

[41] Composto, R.; Chuang, H.-J. In NonconVentional Lithography and Patterning: Techniques and Applications; Bucknall, D., Ed.; WoodHead Publishing: Cambridge, 2005.

[42] Alioscka Sousa, Merih Sengonul, Robert Latour, $\dagger$ Joachim Kohn, $\$$ and Matthew Libera,Selective Protein Adsorption on a Phase-Separated SolventCast Polymer Blend, Langmuir 2006, 22, 62866292. doi:10.1021/la053081r

[43] Utracki, L. A. Polymer blends handbook, Volume 1, Springer, 2002.

[44] J. W. Longworth, Conformations and interactions of excited states. II. Polystyrene, polypeptides, and proteins, Biopolymers, 1966, 4 (10), pages 11311148. doi:10.1002/bip.1966.360041009

[45] Ayyagari, C.; Bedrov, D.; Smith, G. D. Structure of Atactic Polystyrene: A Molecular Dynamics
Simulation Study, Macromolecules, 2000, 33 (16), 6194-6199. doi:10.1021/ma0003553

[46] Xu,W.; Chen, Y. F.; Hua, Z. Y. Imaging of hydrogen atoms and stacks of phenyl groups on the surface of polystyrene microparticles by scanning tunneling microscopy. Journal of Macromolecular Science, Part B,1997, 36(3),395 - 400.

[47] Hobza, P.; Selzle, H. L.; Schlag, E. W. J. Am. Chem. Soc.1994,116, 3500. doi: $10.1021 / \mathrm{ja} 00087 \mathrm{a} 041$

[48] Jaffe, R. L.; Smith, G. D. J. Chem. Phys. 1996, 105, 2780 .

[49] Hobza, P.; Spirko, V.; Selzle, H. L.; Schlag, E. W. J. Phys. Chem. A 1998, 102, 2501.

doi:10.1021/jp973374w

[50] Tsuzuki, S.; Uchimaru, T.; Matsumura, K. ; Mikami, M.; Tanabe, K. Chem. Phys. Lett. 2000, 319, 547. doi:10.1016/S0009-2614(00)00170-6

[51] Tsuzuki, S.; Honda, K.; Uchimaru, T.; Mikami, M.; Tanabe, K. J. Am. Chem. Soc., 2002, 124, 104. doi:10.1021/ja0105212

[52] Sinnokrot, M. O.; Valeev, E. F.; Sherrill, C. D. J. Am. Chem. Soc. 2002, 124, 10887. doi:10.1021/ja025896h

[53] Zhikol, O. A. ; Shishkin, O. V.; Lyssenko, K. A.; Leszczynski, J. J. Chem. Phys. 2005, 122,144104.

[54] Waller, M. P.; Robertazzi, A.; Platts, J. A.; Hibbs, D. E.; Williams, P. A. J. Comput., Chem. 2006, 27, 491. doi:10.1002/jec. 20363

[55] Park, Y. C.; Lee, J. S. J. Phys. Chem. A 2006, 110, 5091. doi:10.1021/jp0582888

[56] Puzder, A.; Dion, M.; Langreth, D. C. J. Chem. Phys. 2006, 124, 164105.

[57] Hill, J. G.; Platts, J. A.; Werner, H-J. Calculation of Intermolecular Interactions in the Benzene Dimer using Coupled-Cluster and Local Electron Correlation Methods. Phys. Chem. Chem. Phys. 2006, 8, 4072-4078. doi:10.1039/b608623c

[58] Grimme, S. J. Chem. Phys. 2003, 118, 9095.

[59] Sinnokrot, M. O.; Sherrill, C. D. J. Phys. Chem. A 2004, 108, 10200-10207. doi:10.1021/jp0469517

[60] Heßelmann, A.; Jansen, G.; SchStz, M. J. Chem. Phys. 2005, 122, 014103.

[61] Börnsen, K.O.; Lin, S.H.; Selzle, H.L.; Schlag, E.W. Spectra of Isotopically Mixed Benzene Trimers. $J$. Chem. Phys. 1989, 90 (3), 1299 - 1306.

[62] Henson, B. F.; Venturo, V. A.; Hartland, G. V.; Felker, P. M., Mass-selective ionization-detected 
stimulated Raman spectroscopy of benzene trimer and higher clusters, J. Chem. Phys. 1993, 98(11), 8361-8369. doi:10.1063/1.464544

[63] Engkvist, O.; Hobza1, P.; Selzle, H. L.; Schlag, E. W. Benzene trimer and benzene tetramer: Structures and properties determined by the nonempirical model (NEMO) potential calibrated from the CCSD(T) benzene dimer energies. J. Chem. Phys. 1999, 110, 5758. doi:10.1063/1.478474

[64] Iimori, T.; Aoki, Y.; Ohshima, Y.; S1-S0 vibronic spectra of benzene clusters revisited. II. The trimer. J. Chem. Phys. 2002, 117, 3675.

\section{$\underline{\text { doi: } 10.1063 / 1.1494977}$}

[65] Minea, M.; Moria, H.; Ogataa, M.; Tanakaa, S.; Tsutsuia, T.; Miyoshi, E. Computational research of the electronic structure of benzene trimer cation by ab initio method. Chem. Phys. Lett.2007, 438(4-6), 157-161. doi:10.1016/j.cplett.2007.02.072

[66] Estarellas, C.; Frontera, A.; Quiñoneroa D.; Deyà, P. M. Theoretical ab initio study of substituted benzene trimer: Interplay between hydrogen bonding and $\pi-\pi$ interactions. Computational and Theoretical Chemistry, Available online 11 January 2011. 